\title{
Comparison of motor and cognitive performance of children attending public and private day care centers
}

Mariana M. Santos, Carolina Corsi, Luisa A. P. Marques, Nelci A. C. F. Rocha

ABSTRACT | Background: Given that environmental factors, such as the school environment, can influence child development, more attention should be paid to the development of children attending day care centers. Objective: To determine whether there are differences in the gross motor, fine motor, or cognitive performances of children between 1 and 3 years-old of similar socioeconomic status attending public and private day care centers full time. Method: Participants were divided into 2 groups, 1 of children attending public day care centers ( 69 children) and another of children attending private day care centers ( 47 children). All children were healthy and regularly attended day care full time for over 4 months. To assess cognitive, gross and fine motor performance, the Bayley Scales of Infant and Toddler Development III was used. The Mann-Whitney test was used for comparative analyses between groups of children between 13 and 24 months, 25 and 41 months, and 13 and 41 months. Results: Children in public day care centers exhibited lower scores on the cognitive development scale beginning at 13 months old. The fine and gross motor performance scores were lower in children over the age of 25 months attending public centers. Maternal education was not related to the performance of children in either group. Conclusion: The scores of cognitive performance as well as fine and gross motor performance of children of similar socioeconomic status who attend public day care centers are lower than children attending private daycare centers.

Keywords: physical therapy; children development; day care centers; environment.

\section{HOW TO CITE THIS ARTICLE}

Santos MM, Corsi C, Marques LAP, Rocha NACF. Comparison of motor and cognitive performance of children attending public and private day care centers. Braz J Phys Ther. 2013 Nov-Dec; 17(6):579-587. http://dx.doi.org/10.1590/S1413-35552012005000126

\section{Introduction}

The development of children during the first years of life is characterized by constant biological, psychosocial, and emotional changes that result in significant acquisitions and refinements in the motor, social-affective, and cognitive domains ${ }^{1}$. The child's environment is an important factor in his or her development, as the environment-organism interaction can induce changes in the child's motor skills ${ }^{2}$.

The environmental factors can affect a child's development in a negative or a positive manner. During interactions with the environment, the child's brain is intensely modified, especially along the first years of life, exhibiting substantial synaptic growth, organization, and strengthening, as well as myelination ${ }^{2}$. Factors such as poor socioeconomic conditions $^{3-5}$, low maternal educational levels, and poor quality of the mother-child bond ${ }^{3,4,6,7}$ represent environmental risks for child development. With respect to socioeconomic factors, Peisner-Feinberg ${ }^{8}$ observes that families with higher socioeconomic levels tend to choose better-quality daycare, which accounts for the better performance observed in those populations. Favorable environmental conditions, such as adequate stimuli and appropriate family conditions, seem to exert a positive influence on child development ${ }^{3}$.

Among the environments characteristic of childhood, the influence of the school stands out because it is meant to provide the stimuli and care needed for satisfactory child development ${ }^{7}$. According to Moreira and Lordelo ${ }^{9}$, daycare centers must stimulate the child's development while respecting their dignity and rights.

Some studies have suggested that daycare attendance might increase the risk of behavioral problems, such as lack of discipline and affective insecurity, throughout childhood and adolescence ${ }^{10}$. 
Contrariwise, other studies conducted with populations from low socioeconomic classes stress the relevance of daycare attendance in the promotion of the children's growth and cognitive development ${ }^{11-13}$. To summarize, controversy exists in the literature as to the impact of daycare attendance on the cognitive development and socio-affective behavior of children.

Despite the small number of studies that have assessed the motor development of children attending daycare, factors such as low income, low maternal educational level, and a high children-to-caregiver ratio are held to be the main risk factors for delayed development of motor skills in that population ${ }^{14-16}$. For this reason, several studies pointed to the need to pay more attention to the development of the children who attend preschool education institutions as well as the need to pay more attention to interventions in needy communities to promote the integral health of children ${ }^{16,17}$.

Upon assessing the fine and gross motor performance of five-year-old children, Barros et al. ${ }^{15}$ found that the children attending public schools scored lower on motor scales compared with the children attending private schools. Those findings are consistent with the ones of Cotrim et al. ${ }^{18}$, who reported lower gross motor scores in 10-year-old children attending public schools. With respect to cognitive performance, Sherlock et al. ${ }^{17}$ attributed the better performance of five-year-old children attending state schools to the physical and organizational structures of those institutions in comparison to community schools and the home environment.

However, no study in the literature has yet assessed a full pattern of performance including the fine and gross motor skills and the cognitive skills of children attending full-time public and private daycare centers throughout the first 3 years of life.

Therefore, the aim of the present study was to establish whether there are differences in the fine and gross motor skills and the cognitive performance of children aged 13 to 41 months old belonging to level B of the Brazilian Association of Market Research Companies (Associação Brasileira de Empresas de Pesquisa - ABEP $)^{19}$ socioeconomic classification who attend full-time public and private daycare centers. As some assessments of the Brazilian educational system showed have reported that private daycare centers exhibit better conditions, such as physical structure, toys, and appropriate activities, compared with public daycare centers ${ }^{7,20}$, and as such factors are liable to influence children's development ${ }^{15,18}$, a comparison of healthy children from the same socioeconomic level attending either private or public daycare centers might shed light on the development of children attending those institutions full-time during the first years of life. As a consequence, the hypothesis underlying the present study was that children attending private daycare centers would exhibit better fine and gross motor skills and cognitive performance skills compared with children who attend public daycare centers.

\section{Method}

\section{Participants}

The present study was conducted in a town in the interior of the state of São Paulo with more than 200,000 inhabitants, $7 \%$ of whom are children aged 0 to 5 years-old. The participants were divided in 2 groups: a group of children attending public (GI) and a group of children attending private (GII) daycare centers. With respect to GI, stratified sampling was performed and included the daycare centers in all 5 municipal education districts, taking into account the proportion of children enrolled in full-time public daycare centers. From the 45 public preschool education institutions, 24 tend full-time to children aged 0 to 3 years-old. Ten full-time institutions participated in the study, whereas 4 did not because they had no room available for the children's assessments. As institutions tending preferentially to children aged 0 to 3 years-old were selected, the remaining 10 institutions were not included in the study because they served children older than 3 years old. With respect to GII, convenience sampling was performed because although all 28 private daycare centers that accept children aged 0 to 3 years-old were invited to participate, only 9 agreed.

As a result, GI comprised 68 children, and GII comprised 46 children. In the analysis of the children's performances, both groups were also subdivided according to age ranges, as shown in Table 1. Table 1 further demonstrates that the groups were homogenous with respect to the children's ages, gestational ages (GAs), birth weights, fiveminute Apgar scores, and time since enrolling in the daycare center. The maternal educational level was higher in GII compared with GI, and this difference was significant. 


\section{Criteria of inclusion and non-inclusion}

For inclusion in the study, the children must have attended daycare full-time for at least 4 months; did not exhibit neurological disorders, genetic syndromes, or congenital malformations; had 1- and 5-minute Apgar scores between 7 and 10; exhibited appropriate body weight and height for age $\mathrm{e}^{21}$, and were classified as level $\mathrm{B}$ in the ABEP socioeconomic classification. Level B was selected because it represents an intermediate level exemplified by most of the Brazilian population ${ }^{22}$.

The children were not included in the study when they did not meet the inclusion criteria, were older than 42 months-old; could not be assessed due to crying or irritation; missed the day when assessment was performed; or when their parents refused to provide the socioeconomic data requested and the child's birth date.

All of the children within the investigated age range attending any of the participating schools were invited to take part in the study, and their parents manifested their agreement by signing an informed consent form.

\section{Instruments of assessment}

A "Protocol for Participant Data Collection" was elaborated to record the information on the maternal educational level, GA, birth-weight, Apgar Score, time since enrolling in the daycare center, and the results of the questionnaire relative to the ABEP socioeconomic classification ${ }^{19}$. To establish the socioeconomic level according to that classification, the data collected included the head of the family's educational level, the number of employees at home, such as monthly paid housemaids, and the presence and number of some items at home, including television sets, radios, bathrooms, cars, washing machines, DVD players, refrigerators, and freezers. Based on the addition of the scores in the various categories, the total scores ranged from 0 to 46, and the socioeconomic level was classified as A, B, C, $\mathrm{D}$, or $\mathrm{E}$. In the present study, children from level B were selected, which corresponds to a score range from 23 to 34 .

The Bayley Scales of Infant and Toddler Development - III (Bayley-III ${ }^{\circledR}$ ) were selected to assess the children's fine and gross motor performance and cognitive performance. Even when there are no references available for the Brazilian population, Bayley-III was selected because it exhibits diagnostic value ${ }^{23}$ and is considered the gold standard for the assessment of development because it provides objective, valid, and reliable measures of the development of children from birth to age 42 months $^{24}$.

Administration of the Bayley-III is performed according to the child's age range, and the initial task corresponds to his or her chronological age. The tasks were scored as indicated in the scale manual, i.e., 1 (one) when the child succeeded in performing the task and zero when he or she did not ${ }^{23}$. Assessment

Table 1. Participant Characteristics.

\begin{tabular}{lccc}
\hline \multicolumn{1}{c}{ Variable } & GI & GII & P \\
Sex & $49 \% \mathrm{M}$ & $45 \% \mathrm{M}$ & $0.060^{*}$ \\
& $51 \% \mathrm{~F}$ & $55 \% \mathrm{~F}$ & $32(13-41)$ \\
Age (months) & $26(13-40)$ & & 14 \\
Age group & & 32 & $0.400^{*}$ \\
$\quad$ 1: 13 to 24 months & 30 & $39(32-42)$ & $0.097^{* *}$ \\
2: 25 to 41 months & 38 & $3135 \pm 543$ & $0.154^{*}$ \\
GA & $38(31-42)$ & $10(7-10)$ & $0.950^{* *}$ \\
Weight at birth (g) & $2936 \pm 650$ & $17.4 \pm 8.6$ & $0.000^{*}$ \\
Apgar 5' & $10(7-10)$ & & $1(2 \%)$ \\
Time enrolled at center (months) & $17.5 \pm 7.4$ & $21(46 \%)$ & $24(52 \%)$ \\
Maternal education & & & \\
Elementary & $7(10 \%)$ & & \\
High school & $55(80 \%)$ & $7(10 \%)$ & \\
College & &
\end{tabular}

GA: Gestational Ages; "Mann-Whitney test; **T test. 
ended when the child failed to perform five consecutive tasks. The individual scores were added and transformed in a standard score that ranged from 1 to 19 , with a mean score of $10 \pm 3^{23}$. Normal scores are considered scores above -1 standard deviation (SD), i.e., the minimum normal score is seven.

The fine and gross motor domains and the cognitive domains of the Bayley-III were used in the present study. The cognitive domain comprises activities assessing concentration and memory skills as well as more complex items, such as abstraction, grouping, and logical reasoning. The fine motor domain involves the manipulation of various objects and drawing lines, whereas the gross motor domain assesses the child's ability to move about, jump, and climb stairs, as well as the child's static and dynamic balance.

\section{Procedures}

The present study complied with Resolution 196/96 of the National Health Council and was approved by the research ethics committee of Central São Paulo University Center (Centro Universitário Central Paulista - UNICEP), São Carlos, SP, Brazil (Protocol no. 031/2011). The private daycare centers and the Municipal Education Secretary of a mediumsize town in the interior of São Paulo were contacted in regard to participation in the study. The parents were invited to participate by means of a letter, which was included in the child's communication notebook. The investigators made themselves available at the end of the school day to provide additional information. Once the parents or guardians signed the informed consent form, they were interviewed by telephone to provide the data included in the "Protocol for Participant Data Collection".

Assessment was performed first at the public daycare centers and then at the private daycare centers from October 2011 to October 2012. The children were individually assessed at the daycare centers in a previously prepared room, taking their sleep, hygiene, and feeding routine into consideration. Following brief contact with the children and the investigator's familiarization with the daycare center, the children were asked to go to the assessment room with the investigator. Whenever the children cried or refused to go, the teachers escorted them to the room until they became familiar with the examiner and the BayleyIII tasks ${ }^{23}$. Each assessment lasted approximately 50 minutes; the first 10 minutes were devoted to the fine motor performance, the following 30 minutes were devoted to the cognitive performance, and the last 10 minutes were devoted to the gross motor performance. This sequence was established to promote concentration and participation and because the sequence facilitates the interaction between the examiner and child throughout the application of the tests. The assessment was interrupted whenever the children cried or became irritated and could be restarted within 24 hours. One single examiner performed all of the assessments following specific training, and the inter-examiner agreement index was 96\% relative to his/her coach.

\section{Statistical analysis}

The data were processed using the software Statistical Package for Social Sciences (version 17.0). The Kolmogorov-Smirnov test was used to test the normality of the data relative to the cognitive $(p=0.000)$, fine motor $(p=0.002)$, and gross motor $(\mathrm{p}=0.000)$ domains. Levene's test established that the data exhibited homogeneity of variance (cognition, $\mathrm{p}=0.968$; fine motor, $\mathrm{p}=0.725$; gross motor, $\mathrm{p}=0.296$ ). Comparison between the full GI and GII (children aged 13 to 41 months old) was performed by means of the Mann-Whitney test.

Comparison was also performed between 2 subgroups defined by age range separately, 1 comprising the children aged 13 to 24 monthsold, and the other comprising the children aged 25 to 41 months-old. Subgroup analysis was performed because Brazilian studies have reported differences in the children's performance beginning at age 2 years-old ${ }^{15,25,26}$. As the groups differed in the maternal educational level, the correlation between maternal education and the child's fine and gross motor and cognitive performance was assessed in both groups by means of Spearman's test. In all of the comparisons, the statistical power and effect size tests were performed using software Gpower (version 3.1.1). In all of the analyses, the significance level was established as 0.05 .

\section{Results}

Table 2 describes the results of the Spearman's test performed to assess the correlation between the maternal educational level and the child's performance in each group. As the data demonstrate, there was no correlation between these variables in any group. 
The results relative to the children's fine and gross motor performance and cognitive performance are depicted in Figure 1. The performance of GI was worse than that of GII, and the difference was significant relative to the cognitive ( $U=655$, $\mathrm{p}<0.000$; size effect $=0.95)$ and fine motor $(\mathrm{U}=1192$, $\mathrm{p}=0.023$; size effect $=0.43$ ) performance, although the difference in the gross motor performance was not statistically significant $(\mathrm{U}=1367, \mathrm{p}=0.205$; size effect $=0.20$; power $=27 \%$ ).

The results of the fine and gross motor performance and cognitive performance of the children 13 to 24 months-old (M=19.0; $\mathrm{SD}=3.7)$ are depicted in Figure 2, and the results for the children aged 25 to 41 months-old $(\mathrm{M}=32.7 ; \mathrm{SD}=4.3)$ are depicted in Figure 3. With respect to children 13 to 24 months-old, only the cognitive performance exhibited a significant difference between the groups ( $\mathrm{U}=104, \mathrm{p}=0.002$; size effect $=0.86$ ), whereas children 25 to 41 months-old exhibited significant differences in the cognitive $(U=202, p<0.001$; size effect $=1.1$, fine motor $(\mathrm{U}=412, \mathrm{p}=0.019$; size effect $=0.54)$, and gross motor $(\mathrm{U}=435, \mathrm{p}=0.039$; size effect $=0.47$ ) domains.

\section{Discussion}

The aim of the present study was to compare the fine motor, gross motor, and cognitive performance as assessed by the Bayley-III between children aged 13 to 41 months-old attending public and private daycare centers.

With respect to the cognitive performance, the hypothesis underlying the present study was confirmed, as the children attending public daycare centers exhibited lower scores compared with the ones attending private daycare centers, with large effect sizes in all of the investigated age ranges. These findings agree with the results of other studies, which reported poorer cognitive performance in children aged two to six years-old attending public daycare centers ${ }^{10,12,13}$. The authors attributed their findings to the influence of factors such as poor socioeconomic conditions, less than 8 years of maternal schooling, longer daily stays in daycare, and poor-quality stimulation of the children's development.

In the present study, $52 \%$ of the mothers in GII had attended higher education institutions, whereas

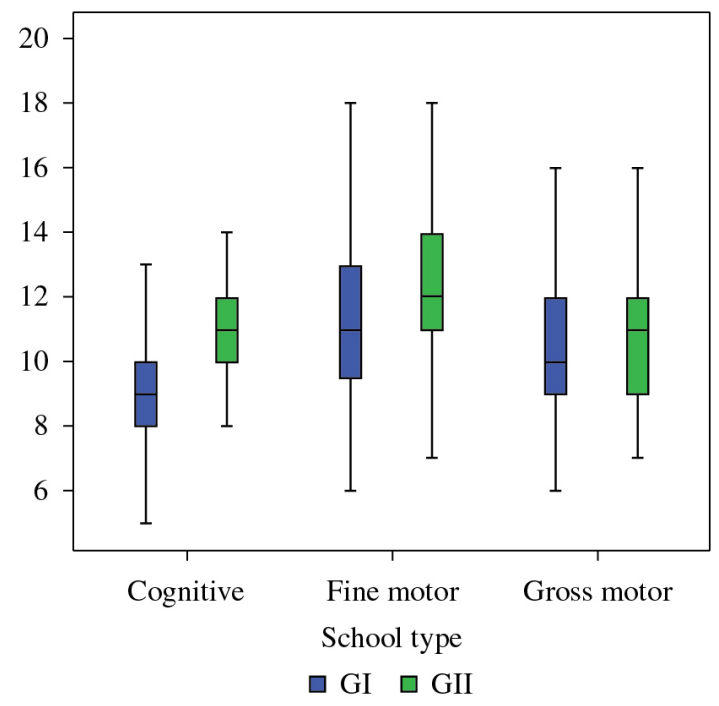

Figure 1. Cognitive, fine motor, and gross motor performance in the municipal day care centers (GI) and private day care centers (GII) for all ages.

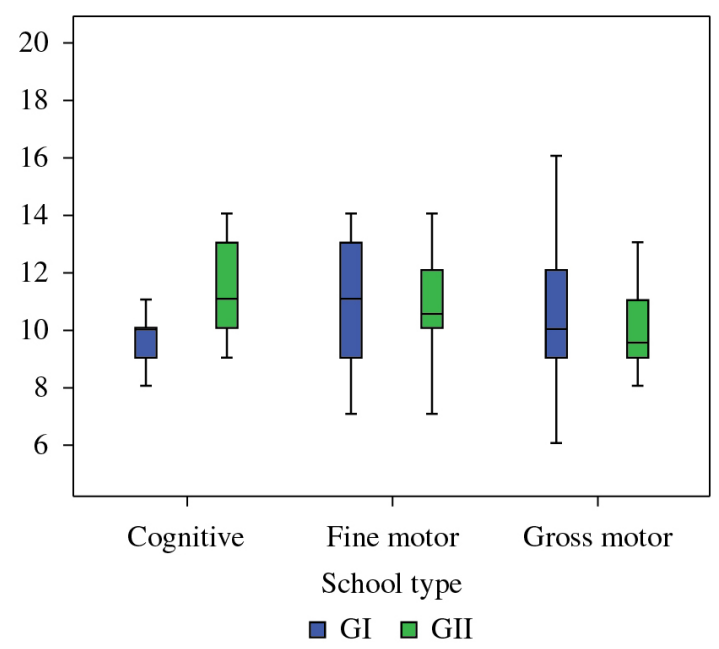

Figure 2. Cognitive, fine motor, and gross motor performance in the municipal day care centers (GI) and private day care centers (GII) for children aged 13 to 24 months.

Table 2. Relationship between maternal education and cognitive development, fine motor performance, and gross motor performance.

\section{Variable}

Cognitive

Maternal Education

GI

GII
$-0.015 \mathrm{p}=0.901$

$0.155 \mathrm{p}=0.308$
Fine Motor

Gross Motor

\begin{tabular}{rrr}
$-0.015 \mathrm{p}=0.901$ & $0.003 \mathrm{p}=0.981$ & $-0.150 \mathrm{p}=0.222$ \\
$0.155 \mathrm{p}=0.308$ & $-0.154 \mathrm{p}=0.307$ & $-0.105 \mathrm{p}=0.487$ \\
\hline
\end{tabular}




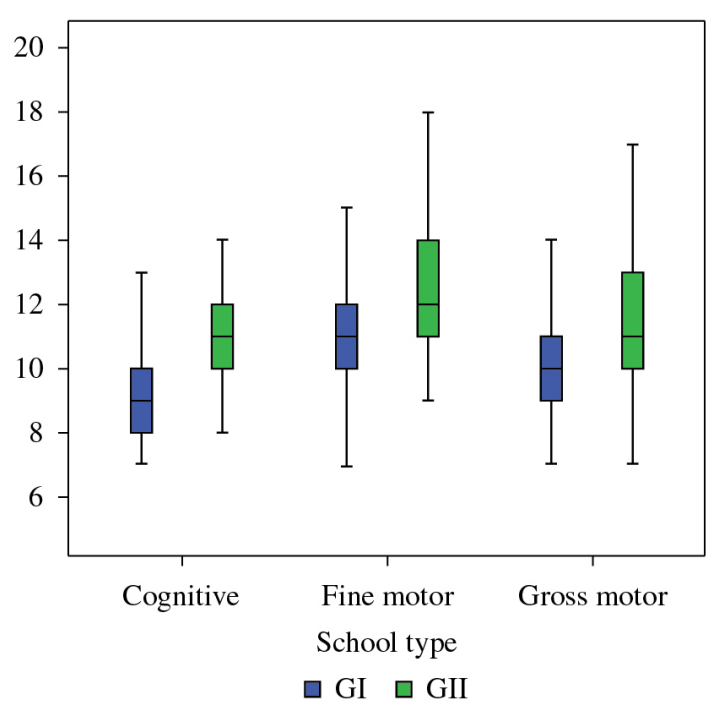

Figure 3. Cognitive, fine motor, and gross motor performance in the municipal day care centers (GI) and private day care centers (GII) for children aged 25 to 41 months.

$80 \%$ of the mothers in GI had finished secondary school but had not pursued further education. As low maternal educational levels are considered a risk factor for child development ${ }^{12,13}$, the higher educational level of the mothers in GII might have represented a difference in stimulation favorable to the children's cognitive development. However, despite the difference in the maternal educational level, no correlation was observed between this variable and the children's performance. Future studies assessing the characteristics of the family environment might better elucidate the relationship among the maternal educational level, stimulation at home, and children performance.

To assess the impact of daycare attendance in public and private institutions, the present study sought to minimize the effects of socioeconomic factors by controlling the socioeconomic level of the participants, and thus only children from $\mathrm{ABEP}^{19}$ classification level B were included. Although all the children thus corresponded to the same socioeconomic level, the $\mathrm{ABEP}^{19}$ classification does not take the family income into account, which might represent an influential factor that was not controlled in the present study. Votruba-Drzal et al. ${ }^{27}$ observe that families with high purchasing power seem to afford better conditions of stimulation for their children. This is because such families are in better financial conditions to purchase appropriate toys and to provide an environment favorable for child development, as when governmental support is lacking, placing a child in a high-quality daycare center is more expensive than leaving him or her with relatives or neighbors ${ }^{28}$.

With respect to the fine and gross motor performance, the effect size of the intergroup comparison tests was average in all of the assessed age ranges. These findings might be due to the characteristics of Brazilian daycare centers, which tend to focus on the children's cognitive development and thus might pay less attention to motor stimulation ${ }^{14,20}$. With respect to fine motor performance, the hypothesis underlying the present study was also confirmed, as the children attending public daycare centers exhibited the lowest scores. However, separate analysis per age range led to an interesting finding, to wit, that such a difference corresponded to the older children only, i.e., the ones aged 25 to 41 months-old. This finding indicates that difference appeared when the scale task complexity increased, e.g., cutting a straight line, copying geometrical shapes, and passing a ribbon through a series of holes ${ }^{23}$. One might infer that those or similar activities were stimulated in the children attending private daycare centers and thus favored the coordination and memory manifested by those children in the performance of the scale tasks. Similarly, upon assessing the fine motor skills of 5-year-old children, Barros et al. ${ }^{15}$ also reported that the children attending public school exhibited poorer performance.

The authors who rate the school environment a risk factor in child development reported limitations in the professionals' training, a predominance of activities targeting nutrition and hygiene in the daily routine, and greater exposure to infectious agents in public schools or in those schools with poor financial resources ${ }^{3,9,15,25}$. Consistently, a lack of activities targeting the acquisition and training of cognitive and motor skills might be the main factor explaining the differences in performance observed in the present study, as goal-directed recreational activities and stimuli-rich environments favor motor development ${ }^{15,16}$.

With respect to gross motor skills, only the children attending public daycare centers aged 25 to 41 months-old exhibited poorer performance. Similar to the case of the Bayley-III fine motor tasks, the gross motor tasks corresponding to that age range are more complex, including climbing up and down stairs unaided, static balance on monopedal stance, 
and long jump ${ }^{23}$. Such tasks demand greater control of the lower limb motions and body balance, and for this reason, successful performance requires experience and training during everyday and/or recreational activities.

The results described corroborate the results reported by Rezende et al. ${ }^{29}$, who reported an increased incidence of suspected development delay in children aged 2 and 3 years-old as a function of the increased complexity of the tasks. This result might be a consequence of the type of activities performed at daycare centers but may also be an effect of home environments that simulate those newly acquired abilities. Although it was not measured, the present study observed that the public daycare centers did not allot a weekly period to directed gross motor activities, whereas the private ones did, including physical education, dance, and/or swimming classes. Directed motor activities contribute to the development of the children's spatial perception, proprioception, and balance ${ }^{29}$ and consequently facilitate the performance of Bayley-III tasks ${ }^{23}$. Nevertheless, other factors such as the physical room, yard size, and presence of equipment promoting the development of such skills should be more thoroughly investigated for proper orientations and stimulation in those environments.

Neither the fine nor the gross motor performance of the children aged 13 to 24 months-old differed between the groups. It is worth observing that the Bayley-III tasks in these domains and age ranges are simple and frequently performed by children everyday, such as block stacking, placing things in containers, walk unaided, throwing a ball, and kicking a ball. We believe that these activities were stimulated in a natural manner in both types of daycare centers, resulting in the lack of discrepancy between the groups.

The poorer cognitive and motor performance exhibited by the children attending public daycare centers indicates that refinement of the motor and cognitive skills results from the dynamic and multidirectional interaction of various organic, environmental, and task-specific factors ${ }^{2}$, as explained by the dynamical systems theory. As the participants in the present study did not exhibit organic structural nor functional disorders, the environmental factor, i.e., the type of daycare center attended, was the factor that seemingly influenced their experiences and caused the differences in the performance of the motor and cognitive tasks. Thus, as the private daycare centers include activities directed by professionals specialized in children's motor functions and thus stimulate psychomotor activities, these centers might have induced greater refinement of the children's motor skills, which was reflected in their better performance compared with the children attending public daycare centers. Family factors, such as greater stimulation at home, might have also contributed to the results; however, the data collected in the present study do not permit conclusions on this influence, as information about the family was not included. However, the maternal educational level did not exhibit a significant correlation with the fine and gross motor performance. Therefore, studies assessing the conditions at public and private daycare centers and focusing on activities that stimulate child development in an adequate manner should be conducted. Although the present study affords a widescoped view of the motor and cognitive performance of children attending public and private daycare centers, it also has some limitations because it did not assess the conditions of stimulation at home, the family income, or the features that distinguish the public and private daycare settings.

The present study identified the need for public policies aimed at promoting child health and education, with an emphasis on the inclusion of professionals skilled in the assessment of the development of children attending daycare centers, the implementation of a program of developmental stimulation, orientation for children caregivers, and assessment of daycare settings.

\section{Conclusion}

The fine motor, gross motor, and cognitive performance of children from the same economic class was lower among children attending public compared with children attending private daycare centers.

The difference in the cognitive performance of children was detectably by 13 months-old, whereas their fine and gross motor performance began to diverge between the ages of 25 and 41 months-old in parallel with the greater complexity of the tasks.

Our findings point to the relevance of monitoring the children's development as well as to the need for measures that ensure adequate stimulation of that population. 


\section{Acknowledgments}

To the National Council of Scientific and Technological Development (Conselho Nacional de Desenvolvimento Científico e Tecnológico - CNPq), Brazil, and the São Paulo Research Foundation (Fundação de Amparo à Pesquisa do Estado de São Paulo - FAPESP), Brazil, for their financial support.

\section{References}

1. Guardiola A, Egewarth C, Rotta NT. Avaliação do desenvolvimento neuropsicomotor em escolares de primeira série e sua relação com o estado nutricional. J Pediatr. 2001;77(3):189-96. http://dx.doi.org/10.2223/ JPED.205

2. Thelen E. Motor development: a new synthesis. Am Psychol. 1995;50:79-95. http://dx.doi. org/10.1037/0003-066X.50.2.79

3. Halpern R, Giugliani ER, Victora CG, Barros FC, Horta BL. Risk factors for suspicion of developmental delays at 12 months of age. J Pediatr. 2000;76:421-8. http:// dx.doi.org/10.2223/JPED.88

4. Barros AJD, Matijasevich A, Santos IS, Halpern R. Child development in a birth cohort: effect of child stimulation is stronger in less educated mothers. Int J Epidemiol. 2010;39:285-94 PMid:19717543 PMCid:PMC2817089. http://dx.doi.org/10.1093/ije/ dyp 272

5. National Institute of Child Health and Human Development Early Child Care Research Network. Duration and Developmental Timing of Poverty and Children's Cognitive and Social Development fron birth through third grade. Child Dev. 2005;76(4):795-810. PMid:16026497. http://dx.doi.org/10.1111/j.1467-8624.2005.00878.x

6. Abbott AL, Bartlett DJ, Kneale Fanning JE, Kramer J. Infant motor development and aspects of the home environment. Pediatr Phys Ther. 2000;12:62-7.

7. Brasil. Ministério da Educação. Secretaria de Educação Básica. Parâmetros Nacionais de qualidade para a educação infantil- volume 1. MEC; 2006. Available from: http://portal.mec.gov.br/seb/arquivos/pdf/Educinf/ eduinfparqualvol1.pdf.

8. Peisner-Feinberg ES. The relation of preschool child-care quality to children's cognitive and social developmetal trajectories through second grade. Child Dev. 2001;72(5):1534-53. http://dx.doi. org/10.1111/1467-8624.00364

9. Moreira LVC, Lordelo ER. Creche em ambiente urbano: ressonâncias no ecossistema desenvolvimental. Interação Psicol. 2002;6(1):19-30.

10. Sagi A, Koren-Karie N, Gini M, Ziv Y, Joels T. Shedding further light on the effects of various types and quality of early child care on infant-mother attachment relationship: the Haifa Study of Early Child Care. Child Dev. 2002;73(4):1166-86.

11. Albers EM, Riksen-Walraven JM, Weerth C. Developmental stimulation in child care centers contributes to young infants' cognitive development. Infant Behav Dev. 2010;33:401-8. PMid:20493531. http://dx.doi. org/10.1016/j.infbeh.2010.04.004

12. Sylva K, Stein A, Leach P, Barnes J, Malmberg LE; FCCteam. Effects of early child-care on cognition, language, and task-related behaviours at 18 months: An English study. Br J Dev Psychol. 2011;29:18-45. PMid:21288253. http://dx.doi.org/10.1348/026151010X533229

13. Claessens A. Kindergarten child care experiences and child achievement and socioemotional skills. Early Child Res Q. 2012;27:365-75. http://dx.doi.org/10.1016/j. ecresq.2011.12.005

14. Barros AJD, Halpern R, Menegon OE. Creches públicas e privadas de Pelotas, RS: aderência à norma técnica. J Pediatr. 1998;74(5):397-403. http://dx.doi.org/10.2223/ JPED.466

15. Barros KM, Fragoso AG, De Oliveira AL, Cabral JE $\mathrm{F}^{\mathrm{o}}$, De Castro RM. Do environmental influences alter motor abilities acquisition? A comparison among children from day-care centers and private schools. Arq Neuropsiquiatr. 2003;61(2):170-5. http://dx.doi. org/10.1590/S0004-282X2003000200002

16. Santos DCC, Tolocka RE, Carvalho J, Heringer LRC, Almeida CM, Miquelote AF. Desempenho motor grosso e sua associação com fatores neonatais, familiares e de exposição à creche em crianças até três anos de idade. Rev Bras Fisioter. 2009;13(2):173-9. http://dx.doi.org/10.1590/ S1413-35552009005000025

17. Sherlock RL, Synnes AR, Koehoorn M. Working mothers and early childhood outcomes: Lessons from the Canadian National Longitudinal study on children and youth. Early Hum Dev. 2008;84:237-42. PMid:17662542. http://dx.doi. org/10.1016/j.earlhumdev.2007.06.003

18. Cotrim JR, Lemos AG, Néri-Junior JE, Barela JA. Development of fundamental motor skills in children with diffrent school contexts. Rev Educ Fís. 2011;22(4):523-33.

19. Associação Brasileira de Empresas de Pesquisa - ABEP. Critério de Classificação econômica. ABEP; 2011. Available from: www.abep.org.

20. Oliveira MA, Furtado RA, Souza TN, Campos-deCarvalho MI. Avaliação de ambientes educacionais infantis. Paidéia. 2003;13(25):41-58.

21. World Health Organization - WHO. Child Growth Charts for babies and children standards. Geneva: WHO; 2006.

22. Instituto Brasileiro de Geografia e Estatística - IBGE. Censo Demográfico 2010 - Famílias e Domicilios. Rio de Janeiro: IBGE; 2010.

23. Bayley N. Bayley Scales of Infant and Toddler Development. 3rd ed. San Antonio: TX, Psychological Corporation; 2005. 
24. Johnson S, Marlow N. Developmental screen or developmental testing? Early Hum Dev. 2006; 82(3):13-83 PMid:16504424. http://dx.doi.org/10.1016/j. earlhumdev.2006.01.008

25. Baltieri L, Santos DCC, Gibim NC, Souza CT, Batistela T, Tolocka RE. Desempenho motor de lactentes frequentadores de berçários em creches públicas. Rev Paul Pediatr. 2010;28(3):283-9. http://dx.doi.org/10.1590/ S0103-05822010000300005

26. Souza CT, Santos DCC, Tolocka RE, Baltieri L, Gibim NC, Habechiam FAP. Avaliação do desempenho motor global e em habilidades motoras axiais e apendiculares de lactentes frequentadores de creche. Rev Bras Fisioter. 2010;14(4):309-15.

27. Votruba-Drzal E, Coley RL, Chase-Lansdale L. Child Care and Low-Income Children's Development: Direct and Moderated Effects. Child Dev. 2004;75(1):296-312 http://dx.doi.org/10.1111/j.1467-8624.2004.00670.x
28. Lordelo ER, Chalhub AA, Guirra RC, Carvalho, CS. Contexto e Desenvolvimento Cognitivo: Freqüência à Creche e Evolução do Desenvolvimento Mental. Psicol Reflex Crit. 2007;20(2):324-34. http://dx.doi.org/10.1590/ S0102-79722007000200019

29. Rezende MA, Beteli VC, Santos JL. Follow-up of the child's motor abilities in day-care centers and pre-schools. Rev Latino-Am Enfermagem. 2005;13:619-25. http:// dx.doi.org/10.1590/S0104-11692005000500003

\section{Correspondence}

\section{Mariana Martins dos Santos}

Rua Ambrósio dos Santos, 406, Planalto Paraíso CEP 13562-000, São Carlos, SP, Brasil

e-mail: mari.santos.fisio@gmail.com 